\title{
A escrita e seus efeitos culturais*
}

\section{RESUMO}

O presente trabalho discute a relação entre tecnologia de comunicação e cultura, tomando o caso específico da escrita e de seus efeitos socioculturais amplos. Assumese assim que a escrita deve ser considerada tecnologia de comunicação. Serão abordados notadamente seus, da escrita, efeitos econômicos, administrativos, legais, religiosos e, finalmente, macrossociais. Trabalharemos especialmente com um conjunto de três autores canônicos para esta discussão, tentando ordenar suas posições heterogêneas num plano conceitual comum. Ao final serão levantadas algumas questões acerca do modo como teorizamos sobre a relação entre escrita e cultura, de modo que se trata aqui, também, de uma discussão do caráter epistemológico das teorias que operam sobre o jogo escrita e cultura, e, mais amplamente, tecnologia de comunicação e contexto cultural.

\section{PALAVRAS-CHAVE}

escrita

meio de comunicação

cultura

\section{ABSTRACT}

The paper discusses the relationship between communication technology and culture, focusing specifically on writing and its effects. In doing so, writing is considered as a communication technology. We discuss its economic, administrative, legal, religious and macro social impacts. The discussion is centered in three canonical scholars for the subject and their respective theories. Finally, some of the epistemologic problems concerning theories linking writing and culture or, more generally, communication technology and culture, are considered.

\section{KEY WORDS}

writing

media

culture
0 presente trabalho discute a relação entre tecnologia de comunicação e cultura, tomando o caso específico da escrita e de seus efeitos socioculturais amplos. Assumese assim o pressuposto de que a escrita deve ser considerada tecnologia de comunicação e de que enquanto tal afeta o meio em que opera. Concordamos com um dos autores de que nos ocuparemos, que chega mesmo a sustentar que até a poesia é uma tecnologia, tecnologia da palavra falada, anterior à tecnologia da palavra escrita (Havelock, 1996, p. 101) esta representada especialmente, para este autor, pelo "alfabeto grego [...] peça de tecnologia explosiva, revolucionária por seus efeitos na cultura humana, de uma maneira que nada tem de exatamente comum com qualquer outra invenção" (Havelock, 1996, p. 14). Serão abordados notadamente seus, da escrita, efeitos econômicos, administrativos, legais, religiosos e, finalmente, macrossociais. Trabalharemos especialmente com um conjunto de três autores canônicos para esta discussão, tentando ordenar suas posições heterogêneas num plano conceitual comum. Ao final serão levantadas algumas questões acerca do modo como teorizamos sobre a relação entre escrita e cultura, de modo que se trata aqui, também, de uma discussão do caráter epistemológico das teorias que operam sobre o jogo escrita e cultura, e, mais amplamente, tecnologia de comunicação e contexto cultural. O horizonte maior do presente trabalho é, portanto, a epistemologia da comunicação, e envolve uma discussão dos paradigmas básicos do tratamento da relação entre comunicação e cultura.

Os autores de que nos serviremos são Jack Goody (1987), Eric Havelock (1996, 1996b) e Marshall McLuhan $(1977,2005)$.

Goody, o menos abordado pelos teóricos da comunicação brasileiros, é um antropólogo interessado nos efeitos sociais da escrita, não necessariamente escrita fonética, e trabalha comparando as sociedades da Mesopotâmia Antiga, contemporâneas ou imediatamente posteriores à invenção da escrita, com as sociedades orais africanas do século passado.

Havelock - cuja penetração junto aos pesquisadores brasileiros do campo da comunicação fica entre a de Goody e a de McLuhan - é um teórico da literatura que se ocupa dos efeitos da escrita fonética na Grécia Antiga. Note-se assim uma diferença em relação a Goody: este trabalha com escritas não fonéticas, aquele com alfabéticas. A introdução da escrita alfabética, dada sua eficácia e facilidade de ensino, permitiu, para Havelock, o letramento da sociedade grega, que passa de um modo de transmissão cultural oral, marcado pela poesia, para outro baseado na escrita, que vai tornar possível, entre outras coisas, a filosofia ocidental.

McLuhan, bem mais conhecido nos meios comunicacionais brasileiros do que os dois primeiros, faz uma 
leitura da história humana considerando os meios de comunicação, escandindo nosso passado (e presente) em três momentos diferentes: as sociedades tribais primitivas, orais; a Galáxia de Gutemberg, cujos dois grandes motores são a escrita fonética e a prensa tipográfica; a Aldeia Global, atravessada pelos meios eletrônicos de comunicação.

Cada um a seu modo pensa o que nos interessa, o modo como a escrita produz efeitos sociais nas culturas em que age.

Serão tratados inicialmente a economia, a administração e o direito, ao que se seguirá uma abordagem dos aspectos religiosos e o que aqui se nomeia macrossocial, a saber, uma apreensão global do conjunto da sociedade. Considerando que Goody é o menos conhecido dos três autores citados, a ele será dada uma atenção ligeiramente maior do que aos outros dois.

\section{Economia, administração e direito}

Goody é sem sombra de dúvida o autor que mais se detém sobre o problema dos efeitos sociais da escrita sobre a economia e a administração. Em primeiro lugar, deve-se destacar que tanto uma como a outra devem ser pensadas levando-se em conta a dimensão religiosa e a dimensão estatal, o templo e o palácio encarnando duas formas coexistentes e eventualmente conflitantes de poder. A economia tem um lugar de honra na medida em que a gênese de escrita se deu ligada a questões econômicas ${ }^{1}$. Comparando as sociedades orais africanas com as sociedades com escrita da Mesopotâmia Antiga, depreendese que o efeito global da escrita é permitir uma maior complexidade (tamanho, duração temporal, distribuição espacial) das transações econômicas. A ausência de escrita, uma vez que faz depender o registro das operações exclusivamente da memória humana, limita a complexidade do que se pode realizar em termos econômicos:

Nas sociedades orais é certamente possível encontrar analogias, precursores, de todas as práticas dos mercadores do Médio Oriente, mas a escrita permite um desenvolvimento em termos de complexidade que seria de outro modo impossível (Goody, 1987, p. 103). ${ }^{2}$

Na medida em que torna explícito o implícito (lema maior da interpretação de Goody dos efeitos da escrita), na medida em que materializa o que de outro modo ficaria retido apenas no cérebro humano, a quantidade de informações que pode ser armazenada e processada aumenta brutalmente, e com essa quantidade a complexidade das operações. Assim, por exemplo, podemos pensar co-participação por ações, operações de crédito "bancário", seguros (Goody, 1987, pp. 91-97) como tantas operações econômicas complexas para as quais a escrita é imprescindível, tanto hoje quanto na Mesopotâmia Antiga. Nota-se assim, com a presença da escrita, uma vida econômica surpreendente nestas sociedades antigas que o senso comum rapidamente tende a encarar como sociedades excessivamente simples: a complexidade é na realidade grande.

A administração da complexidade da economia, ou outra, por seu turno, supõe a presença da escrita. Pensemos no templo como uma instituição nodal no fluxo de pessoas, mercadorias, terras: recebe doações as mais variadas, produz em suas terras, o que depende de mão de obra externa, gere grandes quantidades de oferendas, deve sustentar uma classe improdutiva economicamente de sacerdotes... ora, gerir essa imensa massa de informações é impensável sem a escrita. Daí não ser exagerado sustentar, como faz nosso autor, que a contabilidade e formas primitivas de livro-caixa surgem nas sociedades antigas mesopotâmicas. Por outro lado, o palácio tem semelhantes necessidades de mecanismos objetivos de registro para que possa cobrar impostos, se administrar, sustentar sua nobreza etc. Mas a administração tem ainda um lado civil, ligado aos mercadores, que do mesmo modo que o palácio e o templo necessitavam de modos materiais de armazenagem de informação para efeitos de gerenciamento. A escrita torna assim possível uma mutação nas formas de administração.

Goody refere-se também aos modos como o exercício do direito foi afetado pela presença da lei escrita, em oposição à lei oral tradicional.

Todo grupo social necessita normas, no sentido geral da palavra, independente de serem implícitas ou explícitas, que regem seu funcionamento. $O$ ideal da sociedade primitiva livre é assim, nada mais do que ilusão: toda sociedade é por definição regrada. A invenção da escrita opera primordialmente explicitando normas que anteriormente existiam de modo implícito. Ora, essa explicitação engendra uma série de consequências fundamentais, que nosso autor detalha com bastante cuidado.

Assim, por exemplo, a lei oral é bastante mais dinâmica, flexível a adaptável do que a escrita:

Mas escrevam-se as normas na forma de um código ou decreto, e terão então de fazerem-se esforços deliberados e conscientes para fazer qualquer alteração. Quer isto dizer, o governo nas culturas escritas tem de ocupar-se de legislar em relação a alterações na lei que o costume teria adaptado mais ou menos automaticamente. E onde a lei escrita não foi formalmente alterada recorre-se às ficções legais e outras fontes da lei para adaptar às situações efetivas (Goody, 1987, p. 161).

À mobilidade quase imperceptível da lei oral se contrapõe a imutabilidade da presença objetiva da lei escrita.

Essa maior flexibilidade é, como dito acima, também, correlata das diferenças no modo de alteração da lei em culturas orais e escritas. Nas orais a lei muda imperceptivelmente, se adaptando às sutis mudanças sociais, culturais, ambientais. Sua mudança é cotidiana, gradativa. Nas culturas escritas a mudança dos códigos su- 
põe situações especiais (pensemos por exemplo numa constituinte), que duram um tempo preciso: ao invés de alterações constantes um lapso preciso de tempo dentro do qual a alteração é possível.

Outro traço importante que decorre da presença da escrita é a criação de um grupo específico especializado em lidar com a lei, com seus rituais, jargões, maneirismos.

A escrita afeta não só as fontes da lei e da argumentação jurídica como também a organização da lei. A relação da lei com a sociedade formaliza-se com o advento da escrita. Como já não existe uma adaptação praticamente homeostática de normas, a lei escrita adquire uma espécie de autonomia muito própria, tal como seus órgãos. O tribunal judicial separa-se gradualmente do tribunal régio ou do chefe, adquirindo os seus próprios especialistas altamente instruídos, alguns dos quais são peritos na apresentação oral de casos, argumentando e defendendo a causa do cliente, outros na prestação de conselho. [...] A organização interna do tribunal também se torna elaborada porque o uso de precedentes, e quiçá a lei feita pelos próprios juízes a qualquer escala, exige a manutenção de registros. [...] Os registros escritos implicam a presença de escritores cujo trabalho dá uma forma permanente aos pleitos e decisões verbais. Também os juízes precisam compreender a palavra escrita à medida que a lei é cada vez mais incorporada em resumos e summae. Sob estas circunstâncias, a profissão de jurista torna-se uma ocupação para especialistas letrados, e a lei é cada vez mais retirada das mãos "amadoras" do homem da rua (Goody, 1987, pp. 164-165).

Se Goody especificamente se referiu à administração, à economia e ao direito, o mesmo não se pode dizer de Havelock e McLuhan, que se detiveram mais em outros aspectos (alguns dos quais não discutiremos aqui - subjetividade e epistemologia -, outros sim - aspecto macrossocial).

McLuhan se apóia em Innis, autor fundamental que não trataremos aqui por razões de espaço e tempo, para compreender as transformações sócio-econômicas da invenção da escrita:

Harold Innis, em Empire and Communications, foi o primeiro a tratar desse tema e a explicar com precisão o verdadeiro significado do mito de Cadmo. O rei grego Cadmo, que introduziu o alfabeto fonético na Grécia, segundo se conta, teria semeado os dentes do dragão e deles brotaram homens armados. (Os dentes do dragão talvez se refiram às antigas formas de hieróglifos.) Innis também explicou a razão por que a palavra impressa gera nacionalismo e não tribalismo; e por que cria sistemas de preços e mercados tais que não podem existir sem a palavra impressa. Em suma, Harold Innis foi o primeiro a perceber que o processo de mudança estava implícito nas formas da tecnologia dos meios de comunicação. Este meu livro representa apenas notas de pé de página à sua obra, visando explicá-la (Mcluhan, 1977, p. 82).

O modo como McLuhan fundamenta suas "notas de pé de página" pode ser percebido. De modo geral, os processos fonéticos (e posteriormente a prensa) afetaram a organização subjetiva dos homens dando maior valor ao visual, o que engendra uma mentalidade linear e fragmentada, racional, o que, em última instância, vai ter efeitos amplos em toda a cultura e corpo social (incluindo-se aí direito, administração e economia). Assim teríamos uma economia, um direito, uma administração operando como dimensões separadas e independentes do conjunto da sociedade, baseando-se em técnicas cujo modo de operação seria a linearização, a fragmentação, a racionalização. O rompimento da unidade tribal, por efeito em primeiro lugar da escrita fonética (e posteriormente da prensa tipográfica) é também econômico, administrativo e legal.

Havelock, finalmente, parece se assemelhar bastante a McLuhan. Os diversos modos como a escrita alfabética afetou, para Havelock, a consciência e a epistemologia gregas se refletem, claro, em vários outros campos, incluindo-se administração, economia e direito. Assim por exemplo, especificamente,

[...] em The greek concept of justice: From its shadow in Homer to its substance in Plato, Havelock tratou do movimento que Platão levou ao ponto crítico. A objetividade analítica com que Platão tratou do conceito abstrato de justiça não pode ser encontrada em nenhuma das culturas puramente orais conhecidas (Ong, 1998, pp. 121-122).

A escrita permitiria uma "racionalização" do direito, num sentido que parece próximo do de McLuhan. Seguindo pela mesma linha é perfeitamente compreensível que a administração e a economia sejam, indiretamente, afetadas pelas alterações provenientes da presença do alfabeto.

\section{Religião e aspecto macrossocial}

O esquema básico de explicação de McLuhan que vimos acima em ação pode ser estendido para o campo da religião, opondo de um lado o mundo mágico integrado e holista das culturas orais a um mundo escrito desencantado e separado, o eletrônico religando o que o impresso e o alfabético separaram.

Pense-se por exemplo na experiência das crianças,

[...] isto é, uma criança em qualquer meio ocidental está cercada por uma tecnologia visual abstrata e explícita de tempo uniforme e de espaço contínuo e 
também uniforme, em que a "causa" é eficiente e contínua e as coisas se movimentam e acontecem em planos distintos e em ordens sucessivas. A criança africana, no entanto, vive no mundo mágico e implícito da palavra oral ressoante. Ela não encontra causas eficientes, e sim causas formais do campo configurativo, tais como as que qualquer sociedade não-alfabetizada cultiva (McLuhan, 2005, p. 41).

Temos assim a magia versus a razão, oralidade versus alfabeto.

Mas podemos pensar historicamente efeitos mais específicos, como a ascensão do militar em detrimento do religioso por efeito da alfabetização.

O alfabeto significou o poder, a autoridade e o controle das estruturas militares, a distância. Quando combinado com o papiro, o alfabeto decretou o fim das burocracias templárias estacionárias e dos monopólios sacerdotais do conhecimento e do poder. [...] O alfabeto acessível, juntamente com o papiro transportável, barato e leve, produziu a transferência do poder da classe sacerdotal para a classe militar (Mcluhan, 2005, p. 101-102).

Tal asserção deve ser pensada em relação às teses de Goody sobre o papel administrativo templário da escrita pré-alfabética.

Ao mundo mítico-mágico da oralidade, a escrita alfabética, para McLuhan, faz suceder o mundo racionalizado da Galaxia de Gutemberg.

Havelock considera as limitações impostas ao campo religioso pelos modos de comunicação presentes em determinada cultura. Seguindo a linha geral de sua argumentação, é fácil perceber que no Antigo Testamento, suas partes mais antigas:

[...] foram escritas e preservadas numa variante do silabário fenício. Na verdade, esses textos sofreram uma certa reelaboração teológica no período posterior à fundação do Segundo Templo. Mas continua a ser inquestionável que as narrativas originais e as idéias a elas associadas têm uma sintaxe repetitiva; que situações típicas se mostram aí recorrentes, que o relacionamento entre os personagens é até certo ponto simples, e seus atos têm uma qualidade quase ritual. Sentimos a simplicidade do ritmo da composição à medida que se desenvolve o relato. São precisamente essas limitações impostas ao alcance de apreensão possível da experiência humana o que confere ao Antigo Testamento o forte apelo que tem para as pessoas simples como dizemos. O registro de uma cultura que se conforma a essas restrições tem tudo para centrar-se em religião e mitologia, pois ambas tendem a codificar e padronizar a variedade da experiência humana, de modo que o leitor desses escritos tem mais probabilidade de reconhecer aquilo de que o autor está a falar (Havelock, 1996, p. 94).

Ao caráter oral do Antigo Testamento, assim, se opõe o texto escrito do Novo, com tudo que essa alteração implica na perspectiva de Havelock. Como para este autor o meio condiciona os conteúdos que podem ser veiculados, as religiões orais têm assim um caráter mais concreto, de ação, em oposição ao tom abstrato das religiões escritas. A escrita alfabética é correlata de uma abstração maior da religião.

Goody discute amplamente os efeitos da escrita sobre a religião.

O caso egípcio é notável, pois permite ligar os efeitos da escrita sobre a religião a outros fatores amplos. Assim, por exemplo: "No Egito, o aparecimento da escrita parece ser aproximadamente contemporâneo da criação de um estado único e um panteão global" (Goody, 1987, p. 84).

Destacamos arbitrariamente, da pletora de elementos abordados por este autor, alguns pontos que consideramos importantes.

Em primeiro lugar, destaque-se o universalismo das religiões letradas contra o caráter local das orais.

Neste contexto, gostaria de sugerir que uma componente do universalismo, especialmente do universalismo ético, é característico não só do Cristianismo como de todas as religiões mundiais mais importantes e está diretamente relacionada com o seu uso da escrita (Goody, 1987, p. 28).

Além disso, nas sociedades orais, o fenômeno religioso está integrado no conjunto da vida social, não constituindo um domínio separado, como nas sociedades letradas. Assim, a escrita autonomiza o campo religioso em relação a outros campos da vida social. Isso de pelo menos três formas: autonomia administrativa do templo, autonomia política do templo, separação da experiência religiosa.

Essa autonomização é correlata de um processo de endurecimento: as religiões orais são permeáveis a influências estrangeiras, mais sincréticas, flexíveis, dinâmicas. As escritas tendem a classificar o externo como herege, como desvio, são menos permeáveis. Além disso, pode-se dizer que as religiões escritas são religiões de conversão. Goody assim se expressa:

Quando há fronteiras, marcos da espécie envolvida em religiões com Escritura, então não só há seitas dissidentes como indivíduos dissidentes, indivíduos que são apostatas ou conversos. A conversão é uma função das fronteiras que a palavra escrita cria, ou antes, define (Goody, 1987, p. 26).

Ou se está dentro ou se está fora.

Finalmente, vamos considerar as análises de conjunto da sociedade que consideram o efeito da presença da 
escrita. Essas análises tomam a forma de grandes caracterizações, classificações amplas distinguindo diferentes modos de estruturação social: são o que aqui se chamou de aspectos macrossociais.

O trio de autores de que nos servimos trata, evidentemente, do tema.

McLuhan, como se viu, escandi a história das sociedades humanas em três grandes momentos, pensando cada um destes momentos em função dos meios de comunicação presentes. Temos um primeiro momento caracterizado pela presença de comunicação oral, momento de relativa integração dos sentidos humanos e unidade social. Dois elementos operam a passagem ao segundo grande modo de estruturação social: a invenção da escrita alfabética e, posteriormente, a consolidação dessa cultura escrita com a invenção da prensa e a generalização da presença de materiais impressos. A esse segundo momento McLuhan se refere como a Galáxia de Gutemberg. Esta se caracteriza por segmentação, racionalização, linearização, fragmentação etc. $\mathrm{O}$ eletrônico, cujo marco maior pode ser considerado a televisão, promove a superação dessa galáxia do escrito em direção à Aldeia Global, que recupera o sentido de unidade perdida por ação inicialmente da escrita, quando "a separação multi-secular dos sentidos e funções terminou numa unidade completamente inesperada" (McLuhan, 1977, p. 369). Nossa atualidade recupera nossos primórdios, numa curiosa forma de consciência cósmica:

A eletricidade indica o caminho para a extensão do próprio processo da consciência, em escala mundial e sem qualquer verbalização. Um estado de consciência coletiva como este deve ter sido a condição do homem pré-verbal. (...) Em suma, o computador, pela tecnologia, anuncia o advento de uma condição pentecostal de compreensão e unidade universais. O próximo passo lógico seria, não mais traduzir, mas superar as línguas através de uma consciência cósmica geral, muito semelhante ao inconsciente coletivo sonhado por Bergson. A condição de "imponderabilidade", que os biólogos tomam como promessa de imortalidade física, pode ser acompanhada pela condição de "infalibilidade", que asseguraria a paz e a harmonia coletiva e perpétua (McLuhan, 2005, pp. 98-99).

Se considerarmos, o que não é de modo algum problemático, que a Galáxia de Gutemberg define a Modernidade, a Aldeia Global se aproxima radicalmente do que comumente se define como a Pós-Modernidade.

McLuhan não hesita assim em fazer grandes interpretações gerais da cultura em função dos meios de comunicação estruturantes, sendo a escrita fundamental em sua argumentação.

Em Havelock pode-se ler a oposição clara entre dois grandes modos de funcionamento da cultura, um modo oral e um modo escrito. A cultura oral marca-se pela vigência do canto poético como grande mecanismo de transmissão da herança cultural. A lenta passagem para a cultura letrada, correlata da invenção e generalização do uso do alfabeto, é irmã do abandono do canto e da poesia em favor de modos mecânicos de preservação da memória e de toda uma outra forma de transmissão cultural. Envolvendo uma causalidade complexa, o fato é que a invenção do alfabeto produz uma mudança cultural fundamental.

O invento grego fez prevalecer o seu legado nas culturas posteriores, embora, até muito recentemente, os seus efeitos ficassem limitados à Europa e às partes do mundo que a Europa colonizou, incluindo-se aí a América. Se cabe considerá-los revolucionários, a esses efeitos, isto é possível apenas em retrospecto. O curso seguido não foi uma linha reta (Havelock, 1996, p. 327).

\section{Ou ainda:}

A invenção do alfabeto grego, em contraste com os sistemas anteriores, inclusive o fenício, constituiu, na história da cultura humana, um evento cuja importância não foi até agora plenamente captada. Sua aparição separa as civilizações pré-helênicas de todas as que vieram a ser pós-helênicas (Havelock, 1996, p. 188).

A posição de Goody em relação a essas análises globais é bastante refinada e nuançada - pode-se mesmo dizer que vai na contra mão da maior parte dos teóricos contemporâneos - e merece, por isso, uma discussão um pouco mais detalhada que indica o limite mesmo dessas análises excessivamente generalistas ${ }^{3}$.

Este autor, no Prefácio da obra que aqui nos interessa, indica o horizonte maior de seu trabalho:

Ao mesmo tempo, deparo-me com a necessidade de por em causa certas noções acerca do caráter singular do Ocidente no tocante à explicação do aparecimento do mundo "moderno", já que vejo algumas das pré-condições distribuídas de maneira mais geral do que o considerado por muitas das teorias correntes (Goody, 1987, p. 9).

Tal afirmação é melhor compreendida a partir da leitura das últimas páginas da obra:

Em primeiro lugar, temos de contestar a maneira como a categorização formal das atividades humanas, por exemplo, na troca redistributiva ou recíproca, se transforma em tipos ou estágios de sociedade de forma tal que somos levados a considerar que um tipo de atividade não só domina todo o espectro da ação econômica como também exclui outras possibilidades. As possibilidades encontra- 
vam-se muitas vezes já presentes, muito embora subdominantes. Em segundo lugar, é ainda mais necessário indagar as dicotomias e distinções, baseadas mais na intuição que no fato, mais no sentimento que no estudo, que tendem a separar-nos, por meio de um profundo abismo, dos nossos predecessores. [...] Sem dúvida que se contribuiu com muito para o desenvolvimento das culturas humanas em cada um destes períodos, mas pareceria perigoso traçar uma linha divisória demasiado pronunciada entre "nós" e as grandes civilizações do Próximo Oriente Antigo (nem sequer da Índia ou da China), pois elas possuíam e utilizavam uma invenção crítica da humanidade na esfera das comunicações, nomeadamente a escrita, cujo uso não era simplesmente cosmético mas penetrou profundamente em muitas áreas da vida social, permitindo a evolução de novas formas de organização social e novas vias de tratamento da informação. Mais uma vez, há que ter o cuidado de não traçar uma linha demasiado marcada. Muito embora a escrita tenha ajudado a desenvolver novos tipos de operação lógica formal, fê-lo inicialmente tornando explícito o que era implícito nas culturas orais, que não eram nem pré-lógicas nem sequer alógicas, exceto num sentido muito restrito dessas palavras. Esses avisos são necessários porque privilegiar em demasia a experiência européia através de teorias de estágios que nos apartam demasiado desabridamente de outras sociedades leva-nos a precipitar-nos para a hipótese autocongratulatória de que a modernização só poderia ter ocorrido numa área do mundo (Goody, 1987, pp. 202-203).

Temos assim uma relativização da suposta singularidade do Ocidente Moderno que se dá através da indicação de diversos traços normalmente tomados como característicos precisamente da singularidade deste Ocidente, traços que Goody localiza na Mesopotâmia Antiga como efeitos da invenção da escrita (Goody, 1987, p. 204).

Nota-se assim um tipo de abordagem macrossocial diferente das propostas por McLuhan e Havelock. Estes dois operam considerando uma sucessão de épocas qualitativamente distintas, num tipo de análise que se pode qualificar de epocalista. Goody, por seu turno, prefere ver de que modo "as possibilidades encontravam-se muitas vezes já presentes, muito embora subdominantes" (Goody, 1987, p. 202), ou seja, prefere pensar periodizações mais amplas dentro das quais muda o arranjo e a proporção de elementos presentes. É nesse sentido que somos próximos da Mesopotâmia Antiga. A um tipo de pensamento que opera por sucessão diacrônica de épocas diferentes, opõe-se, com Goody, a concepção de que os mesmos elementos estão presentes mudando sua concentração relativa. Assim as diferenças qualitativas ficam relativizadas.

\section{Considerações finais}

Há diversas diferenças entre os autores que mobilizamos na presente discussão.

Diferenças em primeiro lugar de proveniência, na medida em que cada um vem de um campo de saber (antropologia, teoria literária etc.) com seus regimes epistemológicos próprios. Isso implica em modos diferentes de articular seus objetos de pesquisa (efeitos da escrita alfabética, efeitos da escrita em geral, efeitos dos meios de comunicação etc.), suas metodologias, as evidências que sustentam as respectivas posições.

Mas pode-se falar igualmente em diferentes estilos de pensamento, tomando a palavra estilo num sentido propositadamente vago. McLuhan, por exemplo, é o polemista rápido que tem a pretensão de considerar a complexidade da história humana em esquemas extremamente gerais de explicação e com uma falta de cuidado impressionante para com o rigor do detalhe e da demonstração, diferentemente de Goody, este detalhista e cuidadoso. A cada um seu mérito.

A questão que nós, por nosso turno, podemos colocar a todos eles se refere ao modo de ação da tecnologia de comunicação no corpo social.

Adrian Johns indica uma curiosa linhagem na pesquisa sobre os efeitos culturais do livro, contando três nomes de peso, McLuhan, Elizabeth Eisenstein e Bruno Latour. Os três, cada um a seu modo, supõem que a presença dada de uma determinada tecnologia engendra necessariamente certos efeitos, a ação humana na produção do sentido social dessas tecnologias sendo reduzida. "A visão de ciência em ação de Latour depende da 'cultura impressa' de Eisenstein - e assim implicitamente da 'Galaxia de Gutemberg' de McLuhan - para sublinhar a estabilidade tanto do conhecimento quanto da sociedade" (Johns, 1998, p. 14) ${ }^{4}$. Os três operam a partir de um paradigma que se pode qualificar de determinista para pensar a relação entre comunicação e sociedade.

Assim, quanto a McLuhan, o próprio Johns dá a resposta satisfatória (toda a obra de Johns é uma resposta ao determinismo de McLuhan e a Eisenstein), sendo além disso ,moeda corrente sua posição de um forte determinismo tecnológico, resumido na idéia de que o meio é a mensagem. Mas podemos perguntar a Havelock e Goody: qual o espaço de ação dado ao homem face à tecnologia?

Havelock parece se situar numa perspectiva muito próxima da de McLuhan, ou seja, acreditar que a tecnologia é o determinante fundamental, e que sua introdução acarreta necessariamente efeitos individuais e coletivos os mesmos. É a tecnologia, e não o uso ou forma de apropriação social, o importante. Nesse sentido, para Havelock, também o meio é a mensagem, ou seja, uma cultura é estruturada por seus meios de comunicação:

Para compreender o que entendemos por "cultura", inclusive no caso grego, temos de perguntar pelo que lhe dá estrutura, é continuo e assim identificá- 
vel. Esta questão pode ser respondida tomando-se de empréstimo aos antropólogos culturais o conceito de armazenamento de informações para reutilização. A informação em causa não é meramente tecnológica, em sentido estrito, mas também compreende o conjunto de diretrizes que regulam os padrões de conduta dos indivíduos que são membros da cultura (Havelock, 1996, pp. 188-189).

Goody nos parece ter uma posição mais nuançada:

Ao tomar como tópico a escrita e a tradição escrita, por exemplo, não pretendo sequer sugerir que sejam estes os únicos fatores envolvidos em qualquer situação específica, mas apenas que eles são significativos. [...] Como consequência, escolher um tópico significa não só que se corre o risco de inflar a sua importância como, o que é ainda pior, de parecer que se acredita que as questões humanas são determinadas por um único fator (Goody, 1987, p. 13).

Todas as suas análises indicam bem o papel do contexto e da ação humana na gênese, uso e consequentes efeitos sociais da escrita. Assim, a tecnologia é um fator entre outros devendo ser considerada sua composição com outros aspectos da vida social para que seus efeitos ganhem sentido.

A questão do modo de compreensão da causalidade do meio de comunicação é importante na medida em que é um dos primeiros pilares de qualquer teoria que reflita sobre os meios. Além disso, não tem recebido de modo explícito a atenção que merece. Considerando os autores aqui abordados, autores que trataram do tema que ora nos interessa, a saber, os efeitos da escrita, a tendência dominante parece ser enfatizar o meio em detrimento do uso.

Adrian Johns, que citamos acima, dá uma contribuição importante para a questão, na exata medida em que numa obra detalhada e cuidadosa critica a ênfase na tecnologia e o descaso pelas ações humanas na determinação dos efeitos de uma tecnologia, em seu caso o impresso. Todo o trabalho de Johns é refazer a história do livro num sentido mais concreto e menos idealista, $\mathrm{o}$ que o conduz a enfatizar o uso e as apropriações que fazemos das tecnologias.

Em resumo, The Nature of the Book sustenta que a própria identidade da prensa teve de ser feita. Ela vai a ser como agora a experienciamos somente em virtude de trabalho duro, feito por várias gerações em várias nações. (...) The Nature of the Book é a primeira tentativa real de retratar a cultura impressa em sua construção (Johns, 1998, pp. 2-3).

Para este autor, são os usos sociais que condicionam o sentido e a identidade que a tecnologia receberá, sentido e identidade, portanto, contingentes.

Esse ponto permite situar uma reflexão sobre os efeitos culturais da escrita, o que levaria a colocar a pergunta que aparentemente McLuhan e Havelock (poupamos Goody) não colocam, a saber: de que modo os usos da escrita condicionaram seu modo de existência social?

Questão que mais do que nunca merece consideração, mesmo que isso implique no abandono de um certo modo de teorizar marcado, direta ou indiretamente, por um determinismo tecnológico que desconsidera o detalhe da existência histórica em favor de grandes, excessivamente grandes, generalizações ॠFAmEcos

\section{NOTAS}

* Trabalho apresentado ao GT Comunicação e Cultura, do XVIII Encontro da Compós, na PUC-MG, Belo Horizonte, MG, em junho de 2009.

1 Para essa gênese, ligada a moedas simbólicas, ver Goody, 1987, p. 68 e seguintes.

2 Tomamos a liberdade de "abrasileirar" as citações de Goody, cuja obra consultada está no português de Portugal

3 Limite que nós mesmos já discutimos em diversos trabalhos anteriores.

4 A tradução de todas as citações de Johns é nossa

\section{REFERÊNCIAS}

GOODY, Jack. A lógica da escrita e a organização da sociedade. Lisboa: Edições 70, 1987.

HAVELOCK, Eric. A revolução da escrita na Grécia e suas consequências culturais. Rio de Janeiro: Paz e Terra, 1996.

. Prefácio a Platão. Campinas, SP: Papirus, 1996b.

JOHNS, Adrian. The nature of the book: print and knowledge in the making. Chicago and London: The University of Chicago Press, 1998.

McLUHAN, Marshall. A galáxia de Gutemberg: a formação do homem tipográfico. São Paulo: Companhia Editora Nacional, 1977.

Os meios de comunicação como extensões do homem. São Paulo: Cultrix, 2005.

ONG, Walter. Oralidade e cultura escrita: a tecnologização da palavra. Campinas, SP: Papirus, 1998. 